\title{
A comparative study of the relative enzyme inducing properties of anticonvulsant drugs in epileptic patients
}

\author{
E. PERUCCA* A. HEDGES ${ }^{1}$, K. A. MAKKI ${ }^{1 \dagger}$, M. RUPRAH, J. F. WILSON \& A. RICHENS \\ Department of Pharmacology and Therapeutics, Welsh National School of Medicine, Heath Park, \\ Cardiff CF4 4XN and ${ }^{1}$ Department of Clinical Pharmacology, St Bartholomew's Hospital, London EC1A 7BE
}

1 The antipyrine clearance and the urinary excretion of D-glucaric acid (D-GA) were determined in 122 patients receiving chronic anticonvulsant drug treatment and in 21 drug-free control subjects.

2 Patients treated with carbamazepine (CBZ), phenytoin (DPH), primidone (PMD) and phenobarbitone (PB), either alone or in combination, showed higher values of antipyrine clearance and excreted larger amounts of D-GA as compared to controls. While antipyrine clearance values did not differ significantly from one drug group to another, D-GA excretion was significantly higher in patients treated with CBZ than in those treated with DPH.

3 In patients treated with sodium valproate antipyrine clearance did not differ from control values. There was a trend for D-GA excretion to be higher in these patients but the difference was not statistically significant.

4 Significant positive correlations were found between the dosage of CBZ, DPH, PMD and $\mathrm{PB}$ and both indices of enzyme induction. These data demonstrate a dose-dependent degree of enzyme induction in patients receiving therapeutic doses of these anticonvulsants. The relative potency at average dose levels for antipyrine clearance was PB (1), DPH (0.92), CBZ (0.84), PMD (0.82) and for log D-GA excretion was PB (1), CBZ (0.96), PMD (0.95), DPH (0.90).

Keywords anticonvulsant drugs enzyme induction epilepsy

\section{Introduction}

Among the drugs which are known to stimulate the activity of the hepatic microsomal enzymes in man phenytoin (DPH), carbamazepine $(\mathrm{CBZ})$, phenobarbitone (PB) and primidone (PMD) stand in a prominent position. Not only are these anticonvulsants potent enzyme inducing agents when administered in therapeutic doses (Park \& Breckenridge, 1981; Perucca, 1978; Roots et al., 1979; Pirttiaho et al., 1982)

Present addresses: *Clinical Pharmacology Unit, Institute of Pharmacology, Faculty of Medicine, University of Pavia, Pavia, Italy.

†Institute of Pharmacology, University of Basrah, Basrah, Iraq. but they are also usually prescribed on a longterm basis and often in combination. Since inducing properties are at least partially additive (Ohnhaus et al., 1983), it is not surprising for patients treated with these drugs to show evidence of the highest degree of hepatic enzyme induction ever described in man (Perucca, 1978). Because of this, epileptic patients have often been used as a model population for studies into the clinical implications of enzyme induction (Richens \& Woodford, 1976). In order to optimize the design of these studies, however, it would be advantageous if the comparative enzyme inducing potency of the individual antiepileptic drugs 
was known. Although this has been investigated carefully in laboratory animals (Boobis \& Persaud, 1979; Stevenson et al., 1976) these data cannot be extrapolated confidently to the clinical situation. On the other hand, no comparative studies of this kind appear to have been performed in man.

The purpose of the present investigation was to compare two indirect indices of enzyme induction, antipyrine clearance and the urinary excretion of D-glucaric acid (D-GA), in a large population of adult patients receiving long-term therapy with antiepileptic drugs alone and in combination.

\section{Methods}

\section{Subjects}

Twenty-one normal volunteers and 122 epileptic patients, aged between 15 and 67 years, gave their informed consent to participate in the study. Subjects were divided into separate groups according to drug treatment (Table 1). All subjects were Caucasians except for one Asian patient who was included in the DPHtreated group. The age distribution was similar for each group with the exception of patients on the older treatments (PB and PMD) who were on average older than the subjects included in the remaining groups. There was a prevalence of males among the patients treated with DPH and those receiving multiple drug therapy.

Each patient had been receiving the same drug therapy for at least 2 months prior to the study, although in most cases the last change in drug treatment exceeded considerably this period. Patients who had previously been found to have low serum and red cell folate were receiving regular supplements of folic acid (5 $\mathrm{mg}$ daily by mouth) and vitamin $B_{12}(1 \mathrm{mg}$ i.m. monthly). Subjects taking drugs other than anticonvulsants and vitamins and subjects with known endocrine, neoplastic, cardiac, hepatic, renal and febrile disease were excluded from the study. Alcohol intake was minimal or nil in the large majority of patients; a minimal or moderate alcohol intake was admitted to by many of the normal volunteers. No attempt was made to discriminate between the dietary and smoking habits of the various groups.

\section{Evaluation of hepatic microsomal enzyme induction and analytical techniques}

Hepatic microsomal enzyme induction was evaluated in each subject by using two indirect indices of drug metabolizing enzyme activity, antipyrine clearance (Vesell, 1979) and the urinary excretion of D-GA (Hunter et al., 1971). Antipyrine $(18 \mathrm{mg} / \mathrm{kg}$ dissolved in $80 \mathrm{ml}$ water) was administered orally after an overnight fast. Food was not allowed for at least $3 \mathrm{~h}$ afterwards. Blood samples $(10 \mathrm{ml})$ were taken at approximately $4,8,12,24$ and $28 \mathrm{~h}$ after administration. The concentration of antipyrine in serum was measured by gas-liquid chromatography according to Van Boxtel et al. (1976). Clearance, half-life and volume of distribution

Table 1 Details of subjects included in the study. Values shown indicate the mean \pm s.d. and the range.

\begin{tabular}{|c|c|c|c|c|c|c|}
\hline Drug treatment & $\mathbf{n}$ & $\begin{array}{c}\text { Dosage } \\
\left(\mathrm{mg} \mathrm{kg}^{-1} \text { day }^{-1}\right)\end{array}$ & $M$ & $F$ & $\begin{array}{c}\text { Age } \\
\text { (years) }\end{array}$ & $\begin{array}{l}\text { Body weight } \\
\text { (kg) }\end{array}$ \\
\hline Nil (controls) & 21 & - & 10 & 11 & $\begin{array}{l}30 \pm 10 \\
(19-53)\end{array}$ & $\begin{array}{l}66 \pm 12 \\
(52-95)\end{array}$ \\
\hline Sodium valproate & 17 & $\begin{array}{l}13.1 \pm 5.7 \\
(7.1-27.0)\end{array}$ & 8 & 9 & $\begin{array}{l}30 \pm 15 \\
(15-67)\end{array}$ & $\begin{array}{l}63 \pm 9 \\
(54-84)\end{array}$ \\
\hline CBZ & 29 & $\begin{array}{l}14.0 \pm 6.0 \\
(4.2-27.0)\end{array}$ & 15 & 14 & $\begin{array}{l}30 \pm 11 \\
(16-57)\end{array}$ & $\begin{array}{l}67 \pm 12 \\
(47-103)\end{array}$ \\
\hline DPH & 30 & $\begin{array}{l}4.8 \pm 1.5 \\
(2.0-7.7)\end{array}$ & 19 & 11 & $\begin{array}{l}33 \pm 10 \\
(19-58)\end{array}$ & $\begin{array}{l}66 \pm 11 \\
(39-86)\end{array}$ \\
\hline PB & 6 & $\begin{array}{l}3.2 \pm 0.5 \\
(2.4-3.7)\end{array}$ & 4 & 2 & $\begin{array}{l}44 \pm 11 \\
(34-57)\end{array}$ & $\begin{array}{l}64 \pm 9 \\
(50-74)\end{array}$ \\
\hline PMD & 12 & $\begin{array}{c}13.1 \pm 3.0 \\
(8.9-18.3)\end{array}$ & 7 & 5 & $\begin{array}{l}49 \pm 17 \\
(18-65)\end{array}$ & $\begin{array}{l}70 \pm 8 \\
(55-84)\end{array}$ \\
\hline Multiple drug therapy & 28 & $*$ & 20 & 8 & $\begin{array}{l}33 \pm 12 \\
(18-58)\end{array}$ & $\begin{array}{l}66 \pm 9 \\
(52-85)\end{array}$ \\
\hline
\end{tabular}

* Daily dosage in patients receiving combination drug therapy: CBZ $(n=13) 15.5 \pm 5.9 ; \mathrm{DPH}(n=23)$ $4.3 \pm 1.0 ; \mathrm{PB}(n=12) 2.1 \pm 0.6 ; \mathrm{PMD}(n=13) 11.6 \pm 4.3$. 
were calculated according to a one compartment open model on the assumption that absorption was complete.

The concentration of D-GA was determined in $10 \mathrm{ml}$ aliquots of complete $24 \mathrm{~h}$ urine collections according to Marsh (1963). In the many cases in whom two separate urine collections were obtained from the same subject, volumetrically adjusted aliquots of the two specimens were pooled together prior to analysis.

The steady-state serum concentration of antiepileptic drugs was determined by EMIT.

\section{Statistical analysis}

Comparisons between groups Comparisons of parameters of drug metabolizing capacity between groups were made by using the Student's $t$-test for unpaired data. D-GA values were logtransformed prior to analysis.

Correlations Relationships among different parameters were examined by regression analysis. First, multiple regression analysis was performed including only cases with a complete set of data so that comparisons of coefficient of determination values $\left(r^{2}\right)$ could be made with identical data sets. Subsequent specific analyses were made when significant relationships had been demonstrated and all possible data combinations were then included (where appropriate, the number of cases included in each analysis is given in the text).

The design adopted was to take each single drug treatment group in turn and to analyze it in combination with the set of controls. The latter were therefore assumed to be patients on zero dose with zero drug levels. Dose and serum level data were not log-transformed because zero readings cannot be dealt with by such transformation. By using this approach, certain assumptions were being made. First, that drug-treated patients were a continuum with the drug-free controls. Since for most parameters control and drug-treated data overlapped (Figure 1) this was accepted. Secondly, that changes in the parameters of enzyme activity were linearly related to dose. The latter is not generally the case as these measurements have been shown to be log-linearly related (Breckenridge et al., 1973). However, such dose-response studies in animals have employed wide dose ranges and in the present study where dose ranges were all well within 1 $\log$ unit, the lack of the log transformation of dose will be unimportant. This can be verified by inspection of linear fits to the data (Figures 2 and 3 ).
The choice of the regression technique demands linearity in the independent as well as the dependent variable. In the case of D-GA excretion a plot of the actual values $v s$ dose yielded a curved relationship and skewed residuals, whilst the log-transformed data gave linear plots and linear residuals (Figures 2 and 3 ). In the case of the antipyrine data, clearance values could be analyzed without further transformation since analysis of residuals from a regression analysis $v s$ dose gave no evidence of non-linearity. A plot of antipyrine half-life $v s$ dose, on the other hand, yielded skewed residuals indicating non-linearity. In this case a reciprocal transformation $\left(0.693 / t_{1 / 2}=k_{\mathrm{el}}\right)$ linearized the data. The three parameters antipyrine clearance, elimination rate $\left(k_{\mathrm{el}}\right)$ and $\log -\mathrm{D}-\mathrm{GA}$ were therefore used in the analysis.

A further potential problem arises from the use of body weight correction both for drug dosage and the two parameters of drug metabolizing activity, antipyrine clearance and log-DGA. Errors in body weight will produce overestimates in dose/indices of metabolizing capacity correlations. Separate calculations were therefore performed both with and without body weight correction of the metabolic parameters. The use of the weight correction produced small changes in $r^{2}$ values, the range being from +0.027 to -0.097 for the various drug/indices of metabolizing activity combinations. Interference by body weight errors was thus insignificant and body weight correction has been adopted throughout the paper.

\section{Results}

\section{Indices of drug metabolizing capacity in patients subgroups}

Serum drug levels and parameters of drug metabolizing capacity (mean, s.d. and range) in the various subgroups are given in Table 2 . The distribution of antipyrine clearance, half-life and $\log -\mathrm{D}-\mathrm{GA}$ values in each subgroup is illustrated in Figure 1.

There was no difference in antipyrine volumes of distribution among the various subgroups. In patients treated with sodium valproate antipyrine clearance and half-life did not differ from the values observed in drug-free controls whereas the excretion of D-GA tended to be slightly increased (the difference just failed to reach statistical significance $(0.10>P$ $>0.05)$ ). In patients treated with DPH, CBZ, $\mathrm{PB}$ and PMD, alone or in combination, antipyrine clearance and D-GA excretion values were significantly increased. The excretion of 


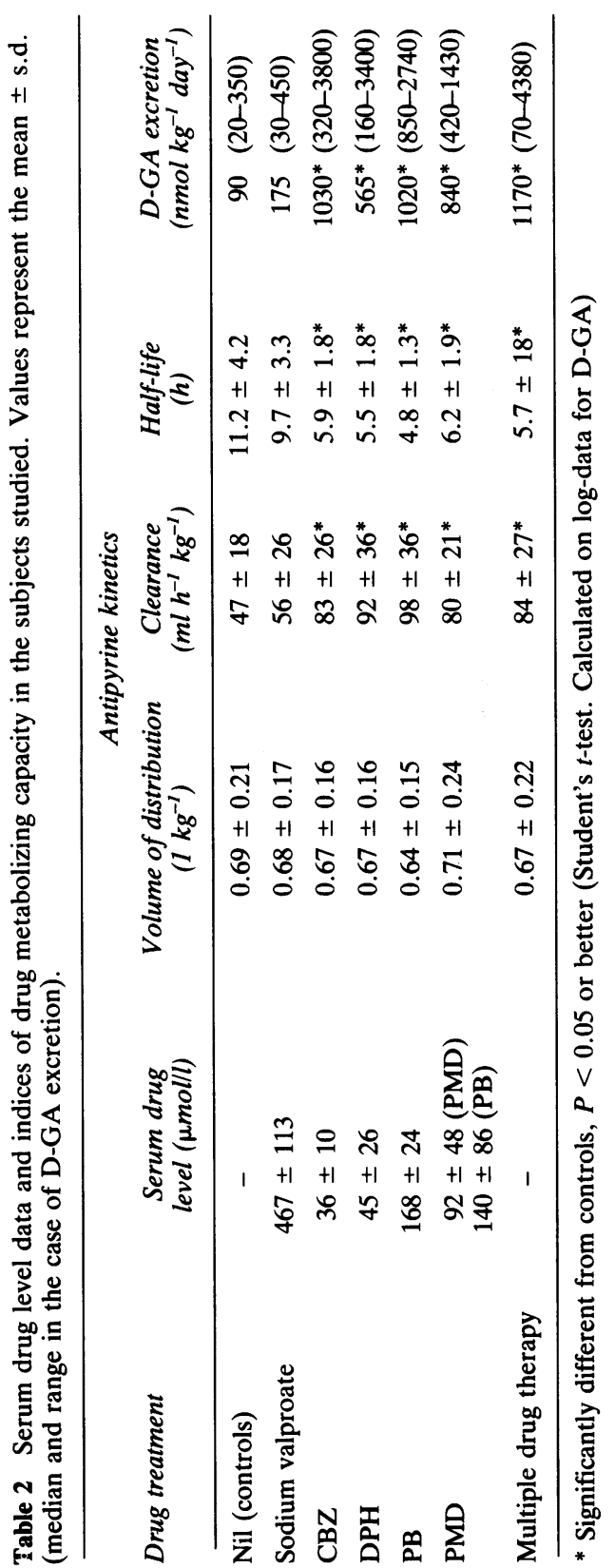

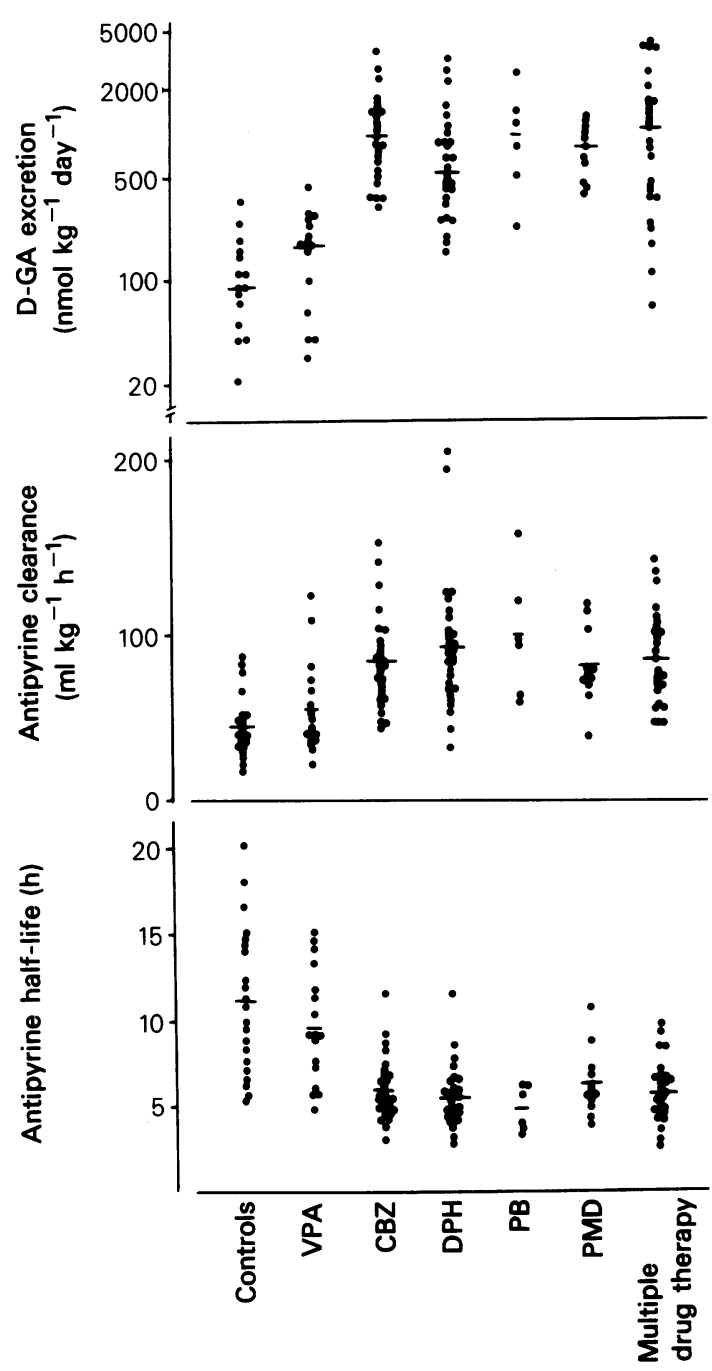

Figure 1 Antipyrine clearance, half-life and D-GA excretion in the various groups. Bars indicate the mean values (median in the case of D-GA).

D-GA was greater in patients treated with CBZ than in those treated with DPH $(P<0.05)$ but the magnitude of the difference was small. No other differences in D-GA excretion or antipyrine kinetics could be found among the groups treated with the above mentioned enzyme-inducing drugs.

\section{Relationship between indices of drug} metabolizing capacity and other variables

The relationship between indices of metabolizing capacity and three independent variables 


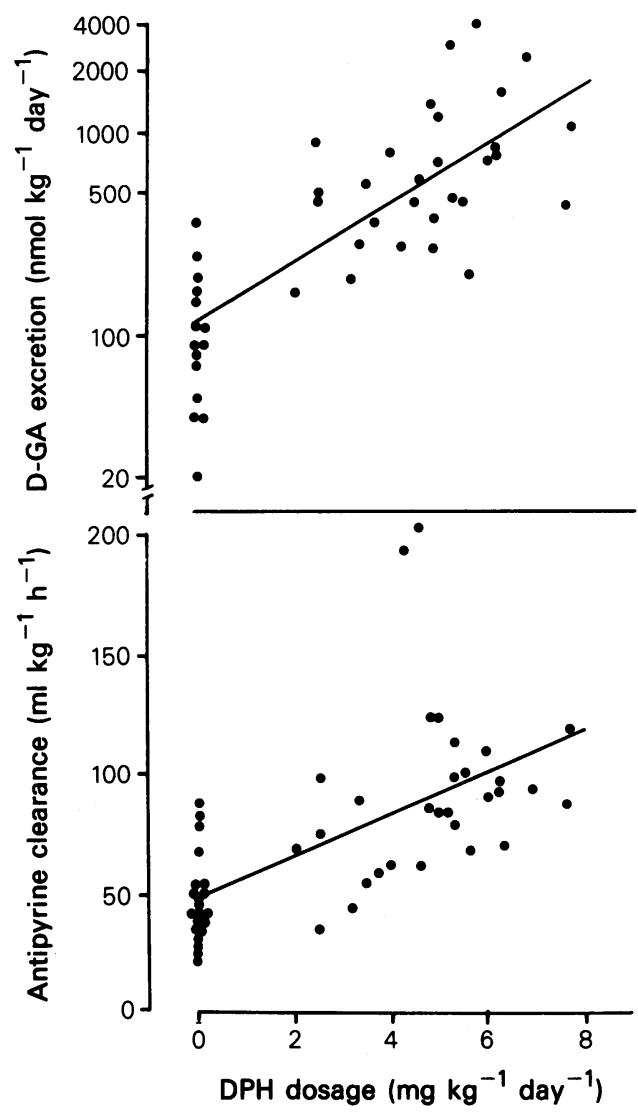

Figure 2 Relationship of DPH dosage with antipyrine clearance and D-GA excretion.

(age, dose and drug level) was investigated separately for each drug group. Controls were included in each set of analysis as previously described.

Valproic acid Multiple regressions of antipyrine clearance, elimination rate and log-DGA with age, dose and drug level failed to show any significant correlation with either the limited or all possible case data groups $(P>0.05)$. Valproic acid thus had no detectable effect on antipyrine kinetics or D-GA excretion.

Carbamazepine In multiple regressions age had no significant effect on antipyrine kinetics or D-GA excretion, contributing less than $3 \%$ to any regression. Highly significant relationships $(P<0.01)$ were demonstrated between either dose or serum levels and the three parameters of metabolizing capacity considered (Figure 3 and Table 3). However, in multiple regressions, when regression with either dose or 

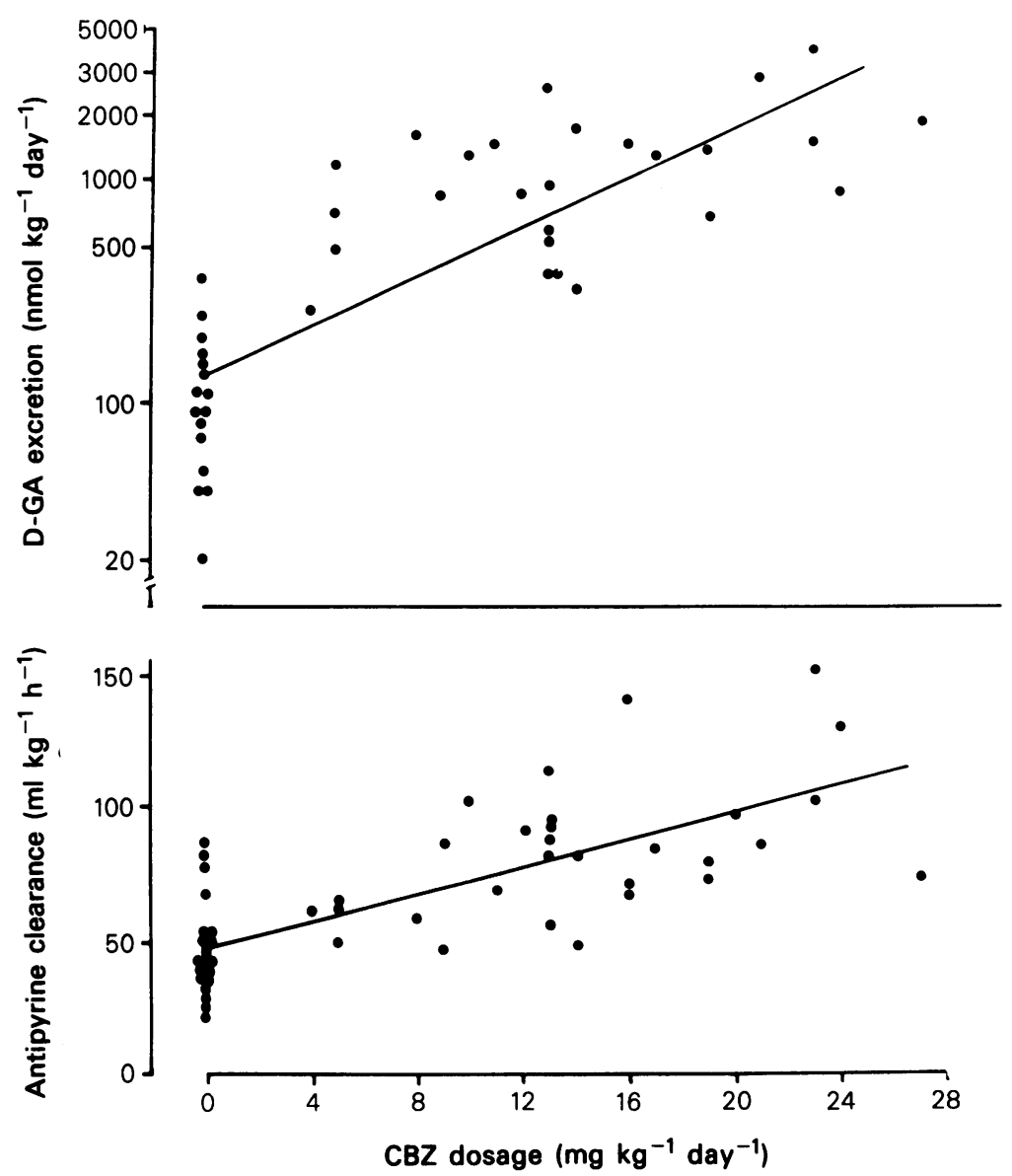

Figure 3 Relationship of CBZ dosage with antipyrine clearance and D-GA excretion.

drug level had been performed addition of the second variable never explained a significant further component of the variation.

Phenytoin As with CBZ, age had no significant effect when added to regressions containing dose and drug level. Significant relationships $(P<0.001)$ were seen between either dose and drug level and the three parameters of metabolizing capacity examined (Figure 2). Dose was always the better predictor and drug concentration failed to explain any further significant part of the variation when added to the regression. $r^{2}$ values from single regressions are shown in Table 3.

Primidone and phenobarbitone Information from multiple regression analysis in these groups was limited because of the smaller number of patients treated with these drugs. Significant relationships $(P<0.05)$, however, could be demonstrated between either dose or serum level and all parameters of metabolizing capacity. In the case of PMD, dose was a better predictor of the variation in these parameters while in the case of PB, dose and serum levels were equally good predictors (Table 3 ). With both drugs, drug concentration when added in a stepwise multiple regression was unable to explain further components of the variation in addition to that already explained by dose. PB was the only drug to show a significant $(P<$ 0.05 ) effect of age on one parameter of enzyme induction. In a multiple regression age accounted for $27 \%$ of the variation in antipyrine clearance data (increasing age being associated with reduced clearance).

Comparison between drugs As described above, with the inducing drugs (CBZ, DPH, $P B$ and PMD) dose was usually the better predictor of metabolizing capacity and there 
was no additional information in the drug level measurements. A consideration of the parameters of metabolizing capacity in relation to dose therefore adequately describes the data and the results of linear regression analysis are shown in Table 4. The intercept values give the parameter value in the drug-free patient and the slope the increase in each parameter for each unit increase in dose. In order to facilitate comparisons between the three indices of drug metabolizing capacity, the dose of drug required to double the indices was calculated from the regression equations and these data are given in the last column of Table 4 . It is apparent that antipyrine clearance and $k_{\mathrm{el}}$ are more sensitive to increased drug dosage compared with the log-D-GA parameter which required approximately twice the drug dose to double the parameter. However, since the variability of the log-D-GA measurements was approximately half that of the antipyrine parameters, all three measures will provide similarly precise estimates of drug-induced changes in liver metabolizing capacity. It should be noted that when D-GA measurements are expressed on a linear scale, as in Table 2, metabolizing capacity and also its imprecision of measurement increase logarithmically with increases in drug dosage.

\section{Prediction of serum drug levels from dose, age and} metabolic capacity

This was evaluated by performing multiple regressions with serum level as the dependent variable and dose, age and one of the three parameters of metabolic capacity as independent variables. For all drugs, serum levels strongly correlated with the prescribed daily dose. The $r^{2}$ values were 0.907 for valproic acid, 0.794 for CBZ, 0.723 for DPH, 0.853 for PMD and 0.980 for PB. Age failed to explain any further component of the variation in serum levels, except for the DPH group where the prediction accuracy increased by $6.2 \%(P<$ $0.05)$ after inclusion of age in the regression. Likewise, the three indices of metabolic activity were usually unable to explain any further significant component of the variation. Only with $\mathrm{CBZ}$ a significant $(P<0.05)$ positive effect was seen when antipyrine $k_{\mathrm{el}}$ data were added to the regression; this, however, caused only a $4.7 \%$ increase in the prediction accuracy of serum CBZ levels from dose information. So, despite significant effects by certain drugs having been demonstrated on metabolic capacity, no significant information appears to be present in the antipyrine or D-GA data which can aid in the prediction of serum levels from dose or other data.

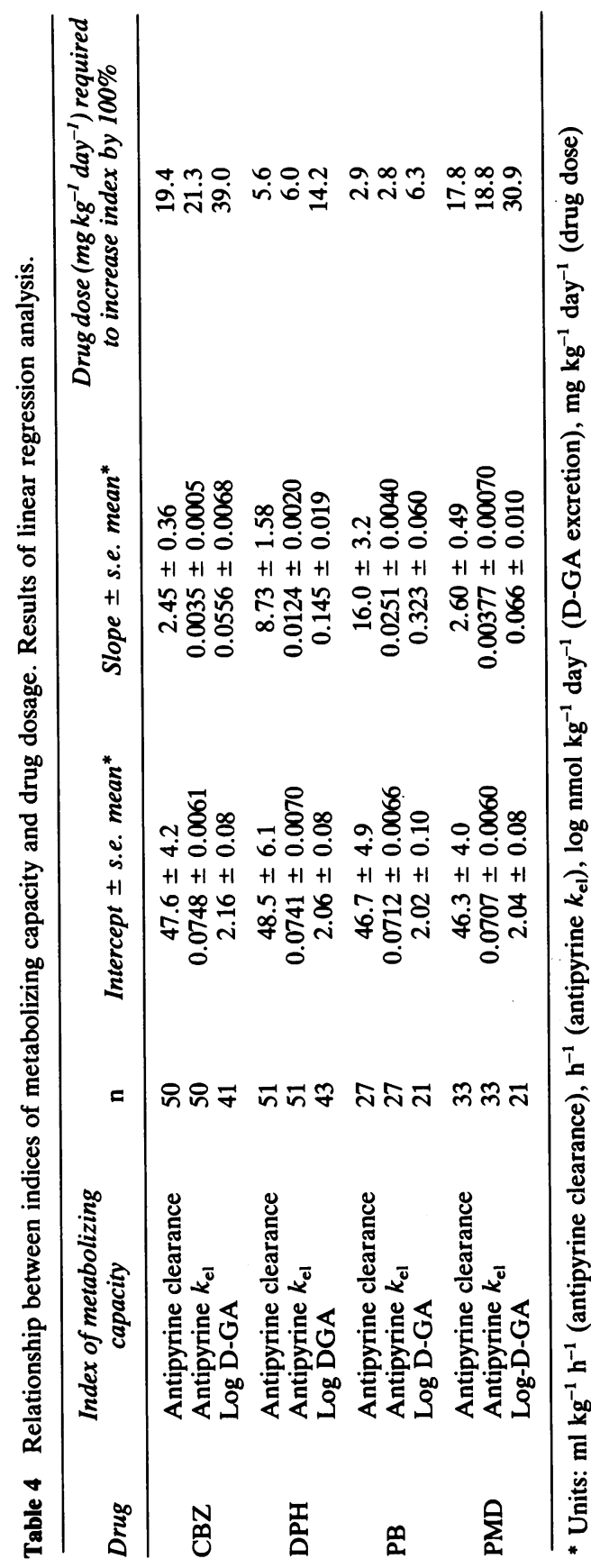


Influence of differences in metabolic capacity on serum drug levels

As described above, knowledge of the indices of metabolic capacity did not appear to improve the predictability of serum drug levels from dose data. This, however, does not exclude the existence of a relationship between indices of metabolic capacity and drug levels. In fact, simple regression analysis between these parameters demonstrates significant relationships for all drugs except valproic acid. The $r^{2}$ values ranged from 0.22 (regression of antipyrine clearance with serum PMD levels) to 0.69 (regression of antipyrine $k_{\mathrm{el}}$ with serum PB levels). So, excluding valproic acid, between 22 and $69 \%$ of the variation in serum levels could be described by differences in parameters of metabolic capacity. This, however, does not imply a causal basis for this relationship, which on the contrary may simply reflect the previously demonstrated correlation between metabolic capacity and drug dosage. In the context of the present data, any influence of metabolic capacity on serum antiepileptic drug levels was so small that it could not be isolated from the major effects of dose and random variation of the data.

\section{Comparison between indices of drug metabolizing capacity}

Within each group (drug-treated patients + controls) antipyrine clearance and $k_{\mathrm{el}}$ values were found to be significantly correlated. The $r^{2}$ values ranged from 0.67 in the valproic acid group $(n=38)$ to 0.84 in the PB group $(n=$ 27). High levels of correlation $\left(r^{2}=0.51-\right.$ 0.75) were also found between $\log$ D-GA values and the two antipyrine parameters for all drugs except valproic acid.

\section{Discussion}

The observation that patients receiving chronic therapy with DPH, CBZ, PB and PMD had significantly higher antipyrine clearances and excreted significantly larger amounts of D-GA as compared to drug-free control subjects confirms that these compounds have marked enzyme inducing properties (Perucca, 1978; Richens \& Woodford, 1976).

The concept of dose-dependent induction (Breckenridge et al., 1973; Ohnhaus et al., 1983) was confirmed by the significant correlations between drug dosage and both antipyrine and D-GA measurements. Comparison of the relative enzyme inducing properties of the four effective drugs requires some knowledge of their relative dosages. The mean doses (Table 1) can be taken as a practical guide to these levels and at these dosages the relative potency of the four drugs was remarkably similar. For antipyrine clearance the relative potencies estimated from the regression data (Table 4) were PB (1), PDH (0.92), CBZ (0.84), PMD (0.82) and for the $\log \mathrm{D}-\mathrm{GA}$ measurements the values were even closer being PB (1), CBZ (0.96), PMD (0.95), DPH (0.90). However, the range of dosages employed was relatively limited and it therefore remains to be established whether the equations of the lines would provide reliable estimates outside this range. It is, nevertheless, of practical interest that, at dosages that are approximately equipotent therapeutically, the four enzyme inducers increased the clearance of antipyrine on average to a similar extent. This would indicate that in clinical practice the four drugs tend to produce an equivalent degree of enzyme induction. It was interesting to note, however, that in the multiple drug treatment group there was no evidence of further additive effects between the enzyme inducing drugs. It is therefore possible that the similarity in inducing potency observed results from levels of stimulation which are causing enzyme induction up to near maximal levels with the dose ranges studied.

The scatter of points around the regression lines relating antipyrine clearance to drug dosage implies that dosage is a poor predictor of the degree of stimulation of antipyrine metabolism in vivo. Addition of serum level data to the regression did not explain any further component of the variation. Among factors that may obscure the dose-effect relationship age did not appear to be important, whereas the role of other variables such as sex, smoking habits (Fraser et al., 1979), diet and folic acid intake (Makki et al., 1980) could not be meaningfully discriminated under the present study conditions.

One important limitation of using antipyrine clearance as a marker of enzyme induction is its poor predictive value in assessing the rate at which the oxidation of other drugs takes place in the in vivo organism. This may be due to the presence of multiple forms of cytochrome P-450 differing in substrate specificity and pattern of reactivity to enzyme inducers (Guengerich, 1979). Antipyrine itself is likely to be metabolized by multiple forms of the cytochrome, one of which may be induced preferentially to others (Danhof et al., 1982). In this context, more specific studies will be required to characterize any differences between the inducing 
properties of individual antiepileptic drugs. That differences exist, at equipotent therapeutic doses, is suggested by the finding of a higher excretion of D-GA in patients treated with CBZ as compared with those treated with DPH. The interpretation of these data, however, must take into account the major limitations of using D-GA as an index of metabolic activity. In fact, the urinary excretion of this metabolite is known to be controlled by nonmicrosomal enzymes and has been reported to correlate poorly with the rate of drug oxidation both in vitro (Lecamwasam, 1975) and in vivo (Smith \& Rawlins, 1974; Ohnhaus \& Park, 1979). In our own study a relatively good correlation could be found between D-GA excretion and both antipyrine clearance and drug dosage: one possible explanation for this is that anticonvulsant drugs exert a dose-dependent effect on the D-GA pathway not related to enzyme induction but going in parallel with it. The apparent discrepancy between our findings and the previously reported lack of correlation between D-GA and other parameters of oxidative metabolism could be due to differences in data analysis (D-GA values, for example, were not log-transformed in some of the earlier studies).

Previous studies on the enzyme inducing properties of sodium valproate in laboratory animals have given equivocal results. Although this drug does not appear to increase cytochrome P-450 content, aniline hydroxylase or aminopyrine- $N$-demethylase activity in rodents (Bonkowsky et al., 1980; Boobis \& Persaud, 1979; Jordan et al., 1976) it is an effective inducer of hepatic $\delta$-aminolaevulinic acid synthetase in the rat and the chick embryo and can markedly increase porphyrin and cytochrome P-450 concentration in chick embryo's cultured hepatocytes (Bonkowsky et al., 1980). Evidence from human data is also inconclusive. While there is no doubt that valproic acid can act as an inhibitor of the oxidative metabolism

\section{References}

Bonkowsky, H. L., Sinclair, P. R., Emery, S. \& Sinclair, J. F. (1980). Seizure management in acute hepatic porphyria: risks of valproate and clonazepam. Neurology, 30, 588-592.

Boobis, S., Persaud, N. (1979). The relative inducing potency of antiepileptic drugs in mice. Br. J. Pharmac., 66, 423P.

Breckenridge, A., Orme, M. L.'E., Davies, L., Thorgeirsson, S. \& Davis, D. S. (1973). Dose dependent enzyme induction. Clin. Pharmac. Ther., 14, 514-520.

Danhof, M., Verbeeck, R. M. A., Van Boxtel, C. J. Boejinga, J. K. \& Breimer, D. D. (1982). of drugs such as phenobarbitone, ethosuximide, and phenytoin (Levy \& Koch, 1982), enzyme inhibition and enzyme induction are not mutually excluding phenomena and the combined occurrence of the two can help in explaining some apparent discrepancies found in the literature. Thus, while Furlanut \& Rizzoni (1980) found a decrease in antipyrine clearance after valproate in all the four children they studied, in other studies valproic acid was reported either not to cause any consistent change in antipyrine half-life and D-GA excretion (Oxley et al., 1979) or actually to induce significantly D-GA excretion (De Wolff et al., 1981; Nemeth \& Szeleczki, 1980). In a similar way, valproic acid has been reported either to be safely used (Michelucci et al., 1981) or to precipitate acute attacks (Garcia-Merino \& Lopez-Lozano, 1980 ) in patients with acute intermittent porphyria. Although in the present study antipyrine clearance and D-GA excretion in valproate-treated patients were not significantly different from controls, there was a trend for at least the D-GA values to be higher in the drug group. This may be a chance finding or simply reflect a minor degree of residual enzyme induction in a few patients who had received other anticonvulsants 2 to 4 months before entering the study. On the other hand, we recently observed a 12-year old girl in whom 6week treatment with sodium valproate $(25 \mathrm{mg}$ $\mathrm{kg}^{-1}$ daily) increased the antipyrine clearance from 65 to $134 \mathrm{ml} \mathrm{kg}^{-1} \mathrm{~h}^{-1}$ and the D-GA excretion from 30 to $110 \mathrm{nmol} \mathrm{kg}^{-1}$ day $^{-1}$. In the light of these data, the widely held view that valproic acid is completely devoid of enzyme inducing properties may need to be re-assessed. It is clear, however, that any enzyme stimulating effect of this drug is likely to be appreciably less than that observed with the other anticonvulsants considered in this study.

We wish to thank the Medical Research Council and the British Epilepsy Association for financial support.

Differential effects of enzyme-induction on antipyrine metabolite formation. $\mathrm{Br} . \mathrm{J}$. clin. Pharmac., 13, 379-386.

De Wolff, F. A., Peters, A. C. B. \& Van Kempen, G. M. J. (1981). Valproate induces urinary Dglucaric acid excretion. Lancet, i, 843.

Fraser, H. S., Mucklow, J. C., Bulpitt, C. J., Kahn, C., Mould, G. \& Dollery, C. T. (1979). Environmental factors affecting antipyrine metabolism in London factory and officer workers. Br. J. clin. Pharmac., 7, 237-243.

Furlanut, M. \& Rizzoni, G. (1980). Effetti del dipropilacetato sulla cinetica dell'antipirina. 
Abstract, Proceedings 20th Meeting of the Italian Pharmacological Society, (SIF), Verona, 1980.

Garcia-Merino, J. A. \& Lopez-Lozaro, J. J. (1980). Risks of valproate in porphyria. Lancet, ii, 856.

Guengerich, F. P. (1979). Isolation and purification of cytochrome P-450 and the existence of multiple forms. Pharmac. Ther., 6, 99-121.

Hunter, J., Maxwell, J. D., Carrella, M., Stewart, D. A. \& Williams, R. (1971). Urinary D-glucaric acid excretion as a test for hepatic enzyme induction in man. Lancet, i, 572-575.

Jordan, B. J., Shillingford, J. S. \& Steed, K. P. (1976). Preliminary observations on the protein binding and enzyme inducing properties of sodium valproate (Epilim $\left.{ }^{\circledR}\right)$. In Clinical and Pharmacological Aspects of Sodium Valproate (Epilim $\left.{ }^{\circledR}\right)$ in the Treatment of Epilepsy, ed Legg, N. J., pp. 112-116. Tunbridge Wells: MGS Consultants.

Lecamwasam, D. S. (1975). Hepatic induction and its relationship to urinary D-glucaric acid excretion in man. Br. J. clin. Pharmac., 2, 546-548.

Levy, R. H. \& Koch, K. M. (1982). Drug interactions with valproic acid. Drugs, 24, 543-556.

Makki, K. A., Perucca, E. \& Richens, A. (1980). Stimulation of drug metabolism by folate replacement in folate deficient epileptic patients. $B r . J$. clin. Pharmac., 9, 304-305P.

Marsh, C. A. (1963). Metabolism of D-glucuronolactone in mammalian systems. Indentification of D-glucaric acid as a normal constituent of urine. Biochem. J., 86, 77-86.

Michelucci, R.. Baruzzi, A. \& Tassinari, C. A. (1981). Valproato di sodio nel trattamento della epilessia associata alla porfiria acuta intermittente. Rivista di Neurobiologia, 28, 309-314.

Nemeth, I. \& Szeleczki, T. (1980). Increased Dglucaric and excretion in children with renal disease. Int. J. clin. Pharmac. Ther. Tox., 18, 357-360.

Ohnhaus, E. E. \& Park, B. K. (1979). Measurement of urinary 6- $\beta$-hydroxycortisol excretion as an in vivo parameter of the clinical assessment of the microsomal enzyme-inducing capacity of antipyrine, phenobarbitone and rifampicin. Eur. J. clin. Pharmac., 15, 139-145.

Ohnhaus, E. E., Gerber-Taras, E. \& Park, B. K. (1983). Enzyme inducing drug combinations and their effects on liver microsomal enzyme activity in man. Eur. J. clin. Pharmac., 24, 247-250.

Oxley, J., Hedges, A., Makki, K. A., Monks, A. \& Richens, A. (1979). Lack of hepatic enzyme inducing effect of sodium valproate. Br. J. clin. Pharmac., 8, 189-190.

Park, B. K. \& Breckenridge, A. M. (1981). Clinical implications of enzyme induction and enzyme inhibition. Clin. Pharmacokin., 6, 1-24.

Perucca, E. (1978). Clinical consequences of microsomal enzyme induction by antiepileptic drugs. Pharmac. Ther., 2, 285-314.

Pirttiaho, H. O., Sotaniemi, E. A., Pelkonen, R. O. \& Pitkänen, V. (1982). Hepatic blood flow and drug metabolism in patients on enzyme inducing anticonvulsants. Eur. J. clin. Pharmac., 22, 441445.

Richens, A. \& Woodford, F. P. (1976). Anticonvulsant drugs and enzyme induction. Amsterdam: Association of Scientific Publishers.

Roots, I., Holbe, R., Hovermann, W., Nigam, S., Heinemeyer, G. \& Hildebrandt, A. G. (1979). Quantitative determination by HPLC of urinary $6 \beta$-hydroxycortisol, an indicator of enzyme induction by rifampicin and antiepileptic drugs. Eur. J. clin. Pharmac., 16, 63-71.

Smith, S. E. \& Rawlins, M. D. (1974). Prediction of drug oxidation rates in man: lack of correlation with serum $\gamma$-glutamyl transpeptidase and urinary excretion of D-glucaric acid and 6- $\beta$-hydroxycortisol. Eur. J. Clin. Pharmac., 7, 71-75.

Stevenson, I. H., O'Malley, K. \& Shepherd, A. M. M. (1976). Relative induction potency of anticonvulsant drugs. In Anticonvulsant drugs and enzyme induction, eds Richens, A. \& Woodford, F. P., pp. 37-46. Amsterdam: Association of Scientific Publishers.

Van Boxtel, C. J., Wilson, J. T., Lindgren, S. \& Sjöqvist, F. (1976). Comparison of the half-life of antipyrine in plasma, whole blood and saliva in man. Eur. J. clin. Pharmac., 9, 327-332.

Vesell, E. S. (1979). The antipyrine test in clinical pharmacology: conceptions and misconceptions. Clin. Pharmac. Ther., 26, 275-286.

(Received July 18, 1983, accepted April 26, 1984) 